\title{
Effect of Heating Atmosphere and Alkali Metal Doping on the Acidic and Basic Sites of Magnesium Oxide
}

\author{
Muhammad Bilal $^{1, ~ *, ~ S a m u e l ~ D a v i d ~ J a c k s o n ~}{ }^{2}$, Alexander Leishman Munnoch ${ }^{3}$, Javed Ali $^{1}$ \\ ${ }^{1}$ Department of Chemistry, Kohat University of Science and Technology, Kohat, Pakistan \\ ${ }^{2}$ School of Chemistry, University of Glasgow, Scotland, UK \\ ${ }^{3}$ Johnson Matthey, Billingham, UK
}

\section{Email address:}

bilalazim4@yahoo.co.uk (M. Bilal), david.jackson@glasgow.ac.uk (S. D. Jackson), alexandermunnoch@gmail.com (A. L. Munnoch), javedgm@yahoo.com (J. Ali)

\section{To cite this article:}

Muhammad Bilal, Samuel David Jackson, Alexander Leishman Munnoch, Javed Ali. Effect of Heating Atmosphere and Alkali Metal Doping on the Acidic and Basic Sites of Magnesium Oxide. International Journal of Materials Science and Applications.

Vol. 5, No. 2, 2016, pp. 36-42. doi: 10.11648/j.ijmsa.20160502.11

\begin{abstract}
Reaction can either be acid or base catalysed. Among the different base catalysed reactions MgO has attracted keen interest from researchers in the last two decades. For different types of reactions different base strength catalyst is required. The basic strength of $\mathrm{MgO}$ can be modified in different ways including alkali metal doping of $\mathrm{MgO}$ which is main aim of this work. Also the acidic and basic properties of which are measured under different atmospheres to demonstrate the impact of this variable. The Alkali doped $\mathrm{MgO}$ catalyst was prepared by impregnation method and the acidic and basic sites were determined using $\mathrm{CO}_{2}$ and $\mathrm{NH}_{3}$. It was found that doping of $\mathrm{MgO}$ with alkali metals significantly decreased the BET surface area and decreased the phase transition temperature for brucite to periclase by about $50^{\circ} \mathrm{C}$. Alkali metal doping also significantly increased the number of basic sites whilst decreasing the number of acidic sites as compared to pure MgO. Under a hydrogen atmosphere the number of basic sites on alkali metal doped $\mathrm{MgO}$ significantly increased.
\end{abstract}

Keywords: Alkali Doped MgO, Acidic and Basic Sites, Effect of Atmosphere

\section{Introduction}

Design and preparation of metal oxides with definite crystallite size, morphology and ordered porosity is the object of several investigations in materials science. These prepared materials consist of two surfaces, the interior pore surface and the exterior particle surface both of which can be purposefully modified to meet a desired purpose. Mesoporosity (pores between 20-500 $\AA$ in diameter) in metal oxides can provide a size and functional group selective micro-environment which provide the desired molecular moieties and shelters these molecules from exposure to the exterior atmosphere [1].

The distinctive structural features of these mesoporous materials are important prerequisites for utilisation in various fields such as: catalysis, chromatographic supports, controlled release of drugs, development of medical implants, miniaturisation of electronic devices, sensor design and formation of semiconductors. In all these applications it is beneficial to understand the structure and energetics of both the perfect and defective oxide surfaces as well as any gas-solid interactions. Many chemical and technological processes (which may use e.g. catalysts or electronic devices) are only feasible because of this understanding [2].

The strength of acidity and basicity of any active sites of solid materials can play a crucial role in their adsorption properties. On the surface of a typical metal oxide, incompletely coordinated metal-centred cations act as acidic centers whereas terminal oxygen species are the basic sites $[3,4]$.

In catalytic studies much attention has been paid to systems containing two intimate but different oxide phases deposited on a support because the interaction between the two components can lead to changes in the surface structure and consequently a modification of their catalytic properties as compared to systems containing such oxides separately [5].

The physico-chemical behavior of supported metal catalysts is dependent upon solid-state interactions between the active phase and the support, however, the addition of 
alkali metals can allow tuning of their catalytic behavior. These effects of alkali promoters on the behavior of heterogeneous catalysts have been associated with electron enrichment of metal particles (electronic effect) - where the metal particles are more electronegative than the doped alkali metal. This influences their interaction paths with reactant/product molecules [6].

Doping of alkali metal on alkaline earth oxides caught the attention of scientists because of the potential utility in various catalytic applications including the conversion of methane to $\mathrm{C}_{2}$ hydrocarbons. Due to the dopant alkali metal cation having a +1 charge, any replacement of alkaline metal oxide cations $(+2$ charge) produce an unpaired electronic hole (found in the oxygen $2 \mathrm{p}$ band). This can localise on one neighboring oxygen ion, so that the defect centre is denoted $\left[\mathrm{M}^{+} \mathrm{O}^{-}\right]$, or be delocalised over the nearest neighbour oxygen ions, which are then partially charged [7].

Magnesium oxide $(\mathrm{MgO})$ can be used as a representative basic catalyst (Hammet constant $H^{-}=+26.0$ ). The $\mathrm{MgO}$ surface is suitable for adsorption experiments; both powders [2] and single crystals [3] have been used as substrates for a large number of atoms and molecules adsorption $\left(\mathrm{N}_{2}, \mathrm{CO}\right.$, $\mathrm{CO}_{2}, \mathrm{CH}_{4}, \mathrm{C}_{2} \mathrm{H}_{6}, \mathrm{NH}_{3}$ and $\mathrm{H}_{2} \mathrm{O}$ ) [7]. Reported advantages of $\mathrm{MgO}$ as a support include: neutralisation of undesirable acidity, control of metal particle size, suppression of carbon deposition, high thermal stability, high pressure stability and low cost [8].

$\mathrm{MgO}$ can be doped with different chemicals to increase its basicity, activity and selectivity for different types of reactions [9]. T. Kanno et al. [10] studied the effect of addition of alkali metals to $\mathrm{MgO}$ and reported that basicity of $\mathrm{MgO}$ increased with the addition of alkali metals. Among the alkali metals lithium has the greatest affect due to its small size which allowed it to be incorporated in the $\mathrm{MgO}$ lattice whilst the effect of caesium is almost zero due to its large size $[10,11]$.

The literature states that alkali metal doping of magnesium oxide increases the material's partial oxidation performance whilst keeping total oxidation activity low [11]. T. Matsuda et al. [12] examined doping of $\mathrm{MgO}$ with different precursors and found that doping of $\mathrm{MgO}$ with sodium increased the basic strength of $\mathrm{MgO}$ and decreased the surface area, especially when sodium nitrate was the dopant. They attributed this basicity increase to the perturbation of the charge distribution over the $\mathrm{MgO}$ upon doping with the alkali metal ions [13].

One of the least discussed catalyst preparation variables in the literature is the effect of material pretreatment and conjointly the pretreatment environment on the resulting catalyst. Such operations, also known in industry as catalyst finishing, are in many cases the key points for activity and selectivity. Therefore the main aim of this research work includes the effects of alkali metal doping on the morphology of $\mathrm{MgO}$. Furthermore the influence of atmosphere during heat treatment on the acidic and basic sites of alkali doped $\mathrm{MgO}$ were investigated.

\section{Experimental}

Pure magnesium oxide and alkali-doped magnesium oxide catalysts were prepared by impregnation using alkali metal nitrate precursors. Sufficient metal nitrate solution was used to produce a metal loading of 4 weight percent. The metal precursor and their $\mathrm{pH}$ values are listed in Table 1.

Table 1. pH of catalyst precursors.

\begin{tabular}{lll}
\hline Catalyst/Support & & Precursor solution $(\mathbf{p H})$ \\
\hline $\mathrm{MgO}$ & - & 11 \\
$\mathrm{Cr}\left(\mathrm{NO}_{3}\right)_{3} .9 \mathrm{H}_{2} \mathrm{O}$ & - & 1.2 \\
$\mathrm{Cr} / \mathrm{MgO}$ & - & $9-10$ \\
\hline
\end{tabular}

The precursors were dissolved in the desired amount of deionised water. The support was then mixed with deionised water separately and their $\mathrm{pH}$ measured. Both precursor and support were then mixed at room temperature and the mixture stirred using a magnetic stirrer. The $\mathrm{pH}$ was measured and was found to range from 9 to 10 . Excess water was removed by rotary evaporator (Buchi Rota vapor R-114) at $80^{\circ} \mathrm{C}$. The catalysts were then transferred to an oven and dried overnight at $110^{\circ} \mathrm{C}$. All catalysts were crushed and sieved to between $250-425 \mu \mathrm{m}$ prior to testing. BET analyses of the materials were undertaken using a Micromeritics Gemini III 2375 Surface Area Analyser. Prior to analyses materials were purged under a flow of $\mathrm{N}_{2}$ overnight at $110^{\circ} \mathrm{C}$ to remove moisture and any physisorbed gases from the catalyst sample. Thermo-Gravimetric Analysis (TGA) was undertaken on a combined TGA/DSC Q600 thermal analyser (requiring only $10-15 \mathrm{mg}$ of material) attached to an ESS Mass Spectrometer where the mass spectrometer analysed evolved gases. For Mass Spectrometric analysis, mass fragments with $\mathrm{m} / \mathrm{z}$ values of $2,14,16,17,18,28,30,32,44$ and 46 (amu) were recorded. To obtain information concerning the phase composition and the distribution of the crystallite sizes of the catalyst before and after reaction, XRD patterns were obtained using a Siemens (D 5000) X-ray Diffractometer $(40 \mathrm{kV}, 40 \mathrm{~mA}$, monochromatic) using a $\mathrm{CuK}_{\alpha}$ source. The scanning range used was $5^{\circ} \leq 2 \theta \geq 85^{\circ}$ with a scanning rate of 2 seconds per step and a step size of $0.02^{\circ}$.

Powder hot stage XRD analysis was also carried out on the Siemens D5000 X-ray Diffractometer using an Anton-Paar XRK reaction cell. The scanning procedure was identical to that for the standard analysis, however the sample was heated in-situ in an argon atmosphere with a heating rate of $12^{\circ} \mathrm{C}$ $\mathrm{min}^{-1}$. Scans were taken at $30^{\circ} \mathrm{C}, 100^{\circ} \mathrm{C}$ and at $100^{\circ} \mathrm{C}$ increments thereafter to $600^{\circ} \mathrm{C}$. At each $100^{\circ} \mathrm{C}$ increment the sample was held for 15 minutes before the scan was taken.

Scherrer equation:

The approximate average crystallite size from the powder XRD pattern was calculated using the Scherrer equation:

$$
\mathrm{d}=\frac{-\mathrm{K} \lambda}{\beta \cos \theta}
$$

Where $\mathrm{d}=$ Average crystallite size $(\AA)$

$\mathrm{K}=$ Scherrer constant $=1$ 
$\lambda=$ wavelength of X-ray source $(1.541 \AA)$

$\theta=2$ theta angle of peak

$\mathrm{B}=$ full peak width at half maximum (FWHM)

Prior to the analysis of acidic and basic properties of the catalyst surface, all samples were in-situ calcined and reduced in a fixed bed quartz microreactor separately at $600^{\circ} \mathrm{C}$ for two hours in argon and hydrogen atmosphere respectively. Following thermal treatment the samples were cooled to room temperature and flushed with argon overnight to avoid the adsorption of gas from atmosphere. The microreactor was then evacuated $1 \times 10^{-1}$ torr to remove the inert atmosphere. A gas loop was attached with adsorbing gas (either $\mathrm{CO}_{2}$ or $\mathrm{NH}_{3}$ ) and a known volume of gas was pulsed over the catalyst with carrier gas. Calibrations were carried out to ensure intensity of peak were directly proportional to the pulse pressure. This was achieved using pulses of varying pressure via a bypass line and calibrated by quadruple EMSS mass spectrometry. After calibration pulses of gas were fed through the catalyst bed at constant intervals until no further adsorption of probe molecules was observed.

To analyse acidic and basic strengths on the catalyst surface pulsing was stopped following catalyst saturation. The catalyst was then heated at $5^{\circ} \mathrm{C} /$ minute from room temperature to $600^{\circ} \mathrm{C}$ in a flow of argon $(10 \mathrm{ml} / \mathrm{min})$ and evolved gas quantified by mass spectrometry. The temperature of the catalyst was measured using a K-type thermocouple located in a quartz capillary immersed in the sample bed.

\section{Results and Discussion}

Table 2. BET surface area of pure and alkali doped $\mathrm{MgO}$.

\begin{tabular}{lllll}
\hline S. No & $\begin{array}{l}\text { Catalyst } \\
\text { Name }\end{array}$ & $\begin{array}{l}\text { BET } \\
\text { Surface }\end{array}$ & BJH Pore & Average Pore \\
\hline & $\mathbf{4 w t} \%$ loading & Area $\left(\mathbf{m}^{2} / \mathbf{g}\right)$ & Volume $\left(\mathbf{c m}^{\mathbf{3}} / \mathbf{g}\right)$ & Diameter $(\AA)$ \\
\hline 1 & $\mathrm{MgO}$ & 113 & 0.20 & 71 \\
$600^{\circ} \mathrm{C}^{*}$ & $\mathrm{MgO}$ & 84 & 0.24 & 113 \\
2 & $\mathrm{NaMgO}$ & 39 & 0.20 & 226 \\
$600^{\circ} \mathrm{C}$ & $\mathrm{NaMgO}$ & 24 & 0.31 & 264 \\
3 & $\mathrm{KMgO}$ & 36 & 0.25 & 262 \\
$600^{\circ} \mathrm{C}$ & $\mathrm{KMgO}$ & 47 & 0.41 & 334 \\
4 & $\mathrm{CsMgO}$ & 46 & 0.30 & 251 \\
$600^{\circ} \mathrm{C}$ & $\mathrm{CsMgO}$ & 62 & 0.43 & 263 \\
\hline
\end{tabular}

* Calcination of sample at $600^{\circ} \mathrm{C}$ for 2 hours

Table 3. Surface Area of $4 w t \% \mathrm{NaMgO}$ at different temperatures.

\begin{tabular}{lllllll}
\hline Temperature $\left({ }^{\circ} \mathbf{C}\right)$ & $\mathbf{1 0 0}$ & $\mathbf{2 0 0}$ & $\mathbf{3 0 0}$ & $\mathbf{4 0 0}$ & $\mathbf{5 0 0}$ & $\mathbf{6 0 0}$ \\
\hline $\begin{array}{l}\text { Surface area }\left(\mathrm{m}^{2} / \mathrm{g}\right) \\
\begin{array}{l}\text { Average Pore } \\
\text { Diameter }(\AA)\end{array}\end{array}$ & 40 & 35 & 36 & 48 & 30 & 24 \\
$\begin{array}{l}\mathrm{BJH} \quad \text { Pore Volume } \\
\left(\mathrm{cm}^{3} / \mathrm{g}\right)\end{array}$ & 0.23 & 0.41 & 0.11 & 0.21 & 0.30 & 0.31 \\
\hline
\end{tabular}

The surface area of doped $\mathrm{MgO}$ is dependent upon the nature of precursor and method of preparation. In the results shown in Table-2 magnesium oxide was doped with alkali metal nitrates and then calcined at $600^{\circ} \mathrm{C}$ for two hours. It can be seen that the BET surface area of the alkali metaldoped magnesium oxide significantly decreased compared to the pure magnesium oxide. It is possible that the alkali metal dopant further facilitates particle sintering. This result is in close agreement with the previous studies [14, 15]. Matsudo et al. [12] mentioned that BET surface area of magnesium oxide decreased due to sintering caused by doping of magnesium oxide with sodium. The effect of temperature on the catalyst BET surface area can be divided into two portions corresponding to the two phases of the catalyst; brucite and periclase. With brucite, an increase in the calcination temperature from $100^{\circ} \mathrm{C}$ to $200^{\circ} \mathrm{C}$ had no significant effect on the BET surface area, whilst the average pore diameter and pore volume significantly increased. This change in average pore diameter and pore volume can be explained by a combination of agglomeration and formation of cracks in the catalyst. Increasing the calcination temperature to $600^{\circ} \mathrm{C}$ brought about little further change in the BET surface area, whilst the pore volume slightly increased. This is attributed to an increase in the number of defects in the crystallites and the evolution of the remaining water present in catalyst framework. Also from literature it was found that above $400^{\circ} \mathrm{C}$ the BET surface area decreased [16].

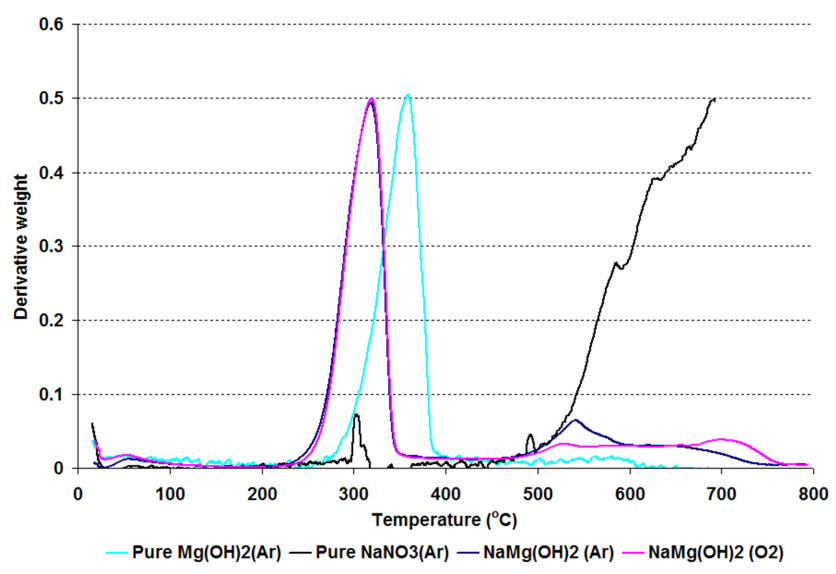

Figure 1. Derivative weight of pure and sodium doped $\mathrm{MgO}$ against temperature from TGA analysis.

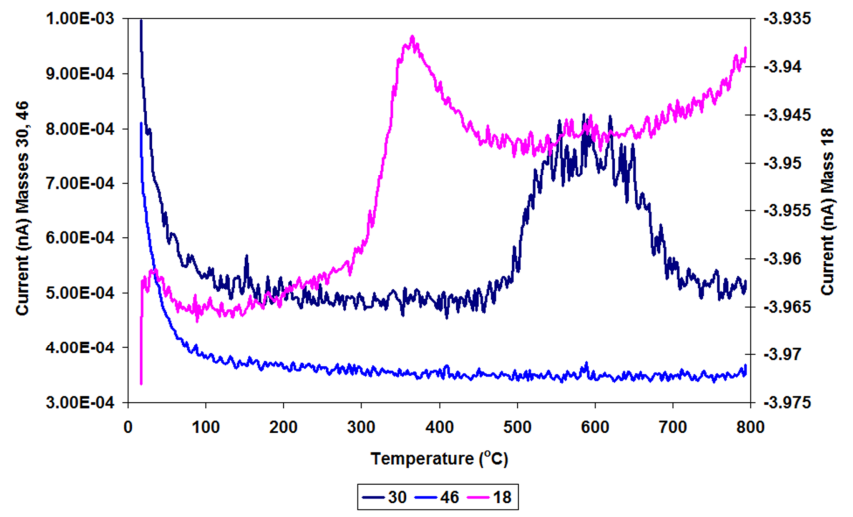

Figure 2. Mass spectrometric data of $\mathrm{NO}(\mathrm{m} / \mathrm{z}=30), \mathrm{NO}_{2}(\mathrm{~m} / \mathrm{z}=46)$ and $\mathrm{H}_{2} \mathrm{O}$ $(\mathrm{m} / \mathrm{z}=18)$ for sodium doped $\mathrm{MgO}$.

The derivative weight loss for the pure and sodium doped magnesium hydroxide are shown in Figure-1. Decomposition of sodium nitrate is also included for comparison. Figure-1 
shows distinct weight losses for both pure and alkali doped magnesium hydroxide in different temperature regions. It shows that a major weight loss $(31 \%)$ occurred between 280 $398^{\circ} \mathrm{C}$. Theoretical calculations for the dehydration of magnesium hydroxide to magnesium oxide gave a similar weight loss $(30.87 \%)$.

$$
\mathrm{Mg}(\mathrm{OH})_{2} \rightarrow \mathrm{MgO}+\mathrm{H}_{2} \mathrm{O} \text { (weight loss }=(30.87 \%)
$$

This result suggests that the weight loss between $280^{\circ} \mathrm{C}$ and $398^{\circ} \mathrm{C}$ represents the conversion of magnesium hydroxide to magnesium oxide. This is supported by the mass spectra (Figure-2), which show that this weight loss is due to desorption of water from the sample. The DSC profile gave a sharp endothermic peak in this temperature region (not shown here), indicating that the dehydration of the sample is an endothermic process, as expected from the decomposition of magnesium hydroxide. This observation is in close agreement to the previous literature [17] that showed that during calcination of magnesium hydroxide to magnesium oxide, the first loss was physisorbed water below $150^{\circ} \mathrm{C}$ and with further heating to $300^{\circ} \mathrm{C}$ the phase transformation of magnesium hydroxide to magnesium oxide and the structural change from hexagonal to cubic structure occurred. It also explained that further heating produced cracking of magnesium oxide crystals into smaller fragments, gradual desorption of the remaining water and sintering of the magnesium oxide crystals. In the current study, the main weight loss took place $\sim 30^{\circ} \mathrm{C}$ higher than the previous report [17]. This can be attributed to the different preparation method, calcination temperature, ramp rate, precursor employed and atmosphere under which the calcination was undertaken.

Decomposition of sodium nitrate was also followed by TGA/DSC with the gases evolved being identified by mass spectrometry to determine at what temperature pure sodium nitrate would form sodium oxide. Figure-1 shows that the decomposition of sodium nitrate starts at $528^{\circ} \mathrm{C}$ continuous till $700^{\circ} \mathrm{C}$ and may above. In mass spectrometry this weight loss matches with evolution of nitrogen monoxide. This indicates that sodium nitrate decompose above $500^{\circ} \mathrm{C}$ to sodium oxide which is congruent to the previous studies [18].

Magnesium hydroxide was impregnated with alkali metal salt in order to study the effect of alkali metal precursor on the structure of magnesium hydroxide. Due to the hydroxylated surface of the $\mathrm{MgO}$, alkali metal nitrates are expected to interact especially during the decomposition process. This interaction between precursor and support effects the decomposition temperature and bond strength of the support. It can be seen from Figure-1 that addition of the precursor to magnesium hydroxide results in differences in the nature of hydroxide decomposition. The weight loss profiles of almost all samples of alkali metal doped $\mathrm{MgO}$ showed a 31 to $40 \%$ weight loss; the bulk of decomposition of alkali doped $\mathrm{MgO}$ occurs in the temperature range of $250^{\circ} \mathrm{C}$ to $350^{\circ} \mathrm{C}$. From mass spectrometry of the TGA gas outlet the first weight loss can be ascribed to $\mathrm{H}_{2} \mathrm{O}$. The second weight loss occurred between $470^{\circ} \mathrm{C}$ and $750^{\circ} \mathrm{C}$ and matched with $\mathrm{NO}$ and $\mathrm{NO}_{2}$ masses in mass spectrometry. It is probable that this may be caused by decomposition of nitrate in the form of NO to form metal oxide. We believe the addition of sodium nitrate to the magnesium hydroxide precursor perturbs the electronic structure of the hydroxide shifting electron density towards the oxygen and further facilitating $\mathrm{Mg}(\mathrm{OH})_{2}$ decomposition.

$$
\mathrm{Mg}(\mathrm{OH})_{2}\left(\mathrm{xH}_{2} \mathrm{O}\right)_{\text {ads }} \underset{(\sim 6 \%)}{\stackrel{50^{\circ}-150^{\circ} \mathrm{C}}{\longrightarrow}} \mathrm{Mg}(\mathrm{OH})_{2}+\mathrm{xH}_{2} \mathrm{O} \underset{93.9 \%}{\stackrel{250^{\circ} \mathrm{C}-350^{\circ} \mathrm{C}}{\longrightarrow}} \mathrm{MgO}+\mathrm{H}_{2} \mathrm{O}
$$

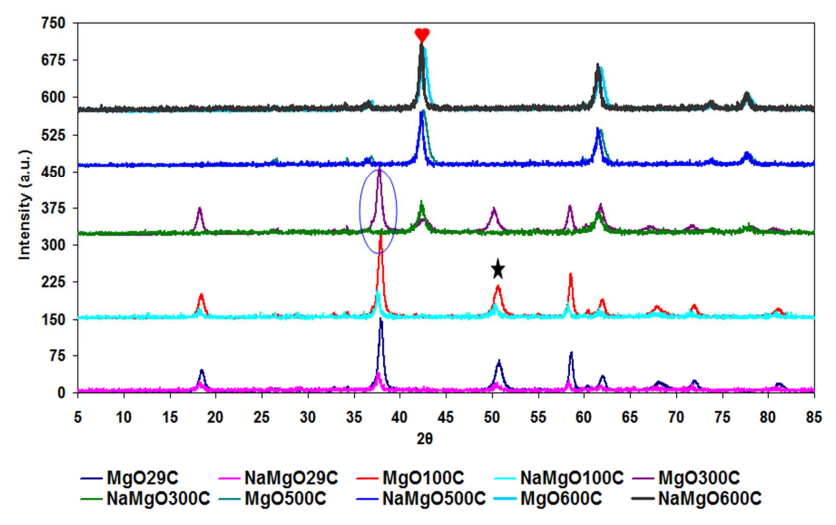

Figure 3. Hot-stage powder XRD patterns of $\mathrm{MgO}$ in an argon atmosphere (The phases denoted are (*) magnesium hydroxide and ( $\checkmark)$ magnesium oxide. The powder XRD patterns are offset for clarity).

Table 4. Average crystallite size of the in-situ calcined $\mathrm{Na} / \mathrm{MgO}$ at different temperatures.

\begin{tabular}{lllllllll}
\hline $\begin{array}{l}\text { Temperature } \\
\left({ }^{\circ} \mathbf{C}\right)\end{array}$ & $\mathbf{2 9}$ & $\mathbf{1 0 0}$ & $\mathbf{2 0 0}$ & $\mathbf{3 0 0}$ & $\mathbf{4 0 0}$ & $\mathbf{5 0 0}$ & $\mathbf{6 0 0}$ & $\begin{array}{l}\mathbf{2 9} \\
\text { final }\end{array}$ \\
\hline $\begin{array}{l}\text { Average } \\
\text { crystallite size } \\
(\AA)\end{array}$ & 254 & 257 & 213 & 129 & 117 & 129 & 103 & 144 \\
\begin{tabular}{l} 
Phase \\
\hline
\end{tabular} & Brucite & & Periclase & & & \\
\hline
\end{tabular}

To investigate the changes in structure and morphology at different temperatures, pure magnesium hydroxide was characterised by hot stage powder X-ray diffraction at different temperatures. Figure-3 shows the hot stage powder XRD patterns for magnesium hydroxide and the products of its progressive heating to various temperatures up to $600^{\circ} \mathrm{C}$. The average crystallite size of the catalyst was determined at different temperatures using the Scherrer equation, as explained in the experimental section, where the average particle size at a given temperature is calculated by the full width half maximum at the most intense peak, as shown in Table-4. Figure- 3 shows that the patterns of the catalyst calcined up to $600^{\circ} \mathrm{C}$ shows the transition between the two phases: brucite $\left(\mathrm{Mg}(\mathrm{OH})_{2}\right)$ and periclase $(\mathrm{MgO})$. The powder XRD patterns at temperatures up to $300^{\circ} \mathrm{C}$ were similar and can be identified as brucite. However, the average crystallite size slightly changed with an increase in the calcination temperature up to $300^{\circ} \mathrm{C}$. Further increase in the calcination temperature changed the patterns of the peaks and new peaks appeared which had smaller crystal sizes and could be identified as periclase. This suggests that the transformation 
of brucite to periclase produced small size crystallites [19]. This phase transformation was also confirmed by the TGA profile, shown in Figure-1. After the phase transformation, further increases in the calcination temperature bring small change in crystallite size up to $600^{\circ} \mathrm{C}$. With the decrease in temperature after calcination at $600^{\circ} \mathrm{C}$, the pattern of periclase was not changed. This suggests that after calcination of the catalyst at $600^{\circ} \mathrm{C}$, a decrease in temperature does not change the phase of periclase back to brucite. The peaks at $2 \theta 37.8^{\circ}$ and $50^{\circ} 2$ theta position are matched with the magnesium hydroxide pattern in the ICDD [20]. The hot stage powder XRD patterns illustrate that doping of magnesium hydroxide with alkali metal nitrate catalysed the decomposition of brucite to periclase and reduced the phase transformation temperature from $400^{\circ} \mathrm{C}$ to $300^{\circ} \mathrm{C}$, as shown in Figure-3. This result is also in keeping with the TGA analysis. The doping of magnesium hydroxide with alkali metal nitrate increased the crystallite size. This is consistent with the results reported by Gilliant [21], who stated that doping of magnesium oxide with $\mathrm{Mn}$ increased the aggregation and increased the crystallite size.

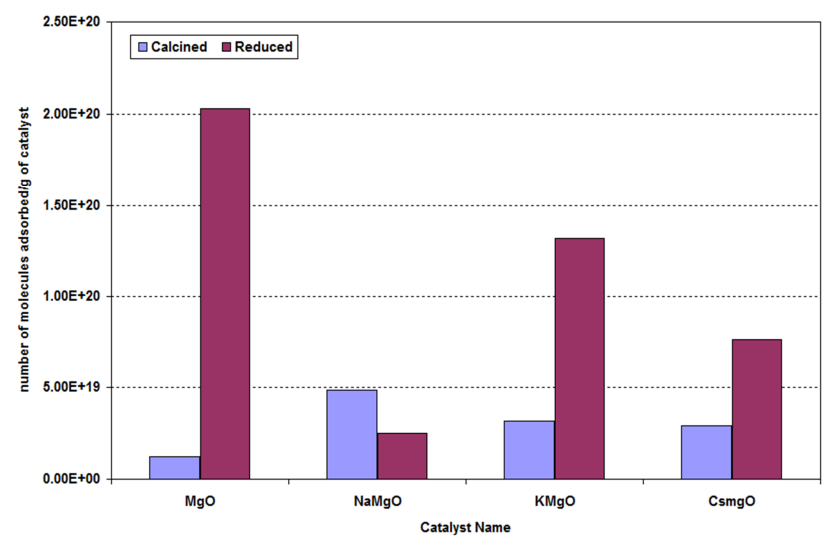

Acidic sites on catalyst.

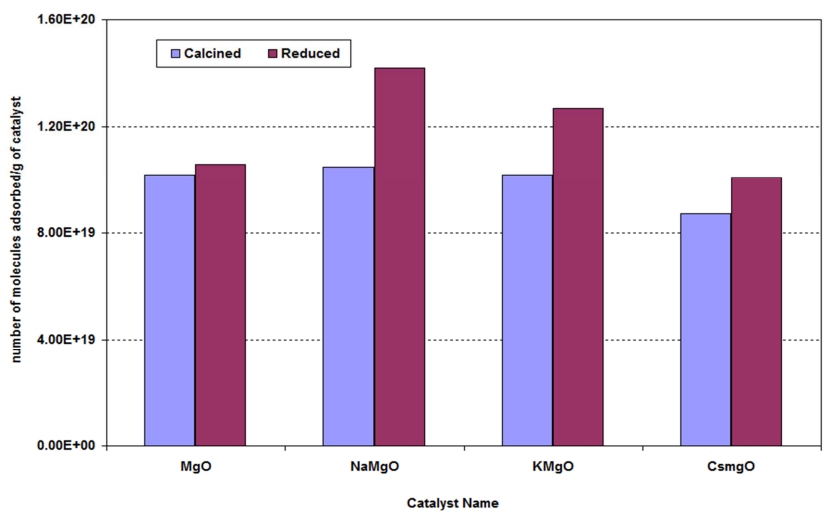

Basic sites on catalyst.

Figure 4. Acidic and basic sites on alkali metal doped $\mathrm{MgO}$.

Figure 4 shows heating of the materials in different atmospheres (calcination in Ar vs. reduction in $\mathrm{H}_{2}$ ) greatly influences the number of acidic and basic sites of the catalyst. Calcination of pure $\mathrm{MgO}$ produced a greater number of basic sites with respect to acidic sites. This may be due to increased removal of $\mathrm{H}_{2} \mathrm{O}$ molecules, leaving metal and defects on the catalyst surface (as schematically represented below).

The terminal oxygen species formed following heat treatment are the primary Lewis base sites. When the sample is heated in hydrogen atmosphere, it accelerates the removal of $\mathrm{H}_{2} \mathrm{O}$ from the brucite structure with a resulting increase in the number of basic sites. Also, the hydrogen atmosphere may interact with surface oxygen species and produce surface hydroxyl groups which act as Brönsted acid sites. As shown in Figure-4 this hypothesis is consistent with the generally higher number of both acidic and basic sites in the reduced material.

Doping of magnesium hydroxide with alkali metal salts and heat treatment results in variation of morphology, decreased surface area and altered numbers of acid/base sites of the magnesium oxide. It may be envisaged that alkali metal cations may interact with $\mathrm{MgO}$ in two ways: firstly that sodium and potassium have similar ionic radii as magnesium ion [22] so incorporation of this metal in $\mathrm{MgO}$ structure and replacement of the $\mathrm{Mg}^{2+}$ ion and secondly the replacement of $\mathrm{Mg}^{2+}$ by $\mathrm{Na}^{+}$and $\mathrm{K}^{+}$with the difference in charge weakening neighbouring $\mathrm{Mg}-\mathrm{O}$ interactions by increasing the relative negative charge on oxygen. This would also be expected to increase the strength and number of basic sites as shown in Figure-4. The effect of atmosphere on both these alkali doped $\mathrm{MgO}$ catalysts is similar. It should not be ignored that the number of acid sites on the sodium doped $\mathrm{MgO}$ in calcined form is slightly greater than the number of basic sites which cannot be explained by this model. There may be some localised electronic effects which complicate the analyses [23]. Addition of caesium greatly influences the number of basic sites in heat treatment under both argon and hydrogen atmospheres whilst the number of acid sites only slightly increases in reduced form. Current results show that heat treatment of $\mathrm{MgO}$ in hydrogen atmosphere produced more acidic and basic sites than argon atmosphere. Also doping of alkali metal on $\mathrm{MgO}$ increases the number of acidic and basic sites.

To determine the strength of the acidic and basic sites on the catalyst surface, temperature programmed desorption of $\mathrm{NH}_{3}$ and $\mathrm{CO}$ were employed respectively using a heating rate of $5^{\circ} \mathrm{C} / \mathrm{min}$ from room temperature to $600^{\circ} \mathrm{C}$. Figure- 5 shows that heat treatment of the catalyst in different atmospheres greatly influence on the acidic and basic strength of the catalyst. The figure indicates that in both atmospheres $\mathrm{NH}_{3}$ desorb at low temperature, indicating weak acid sites on the material [24]. However, in reduced form the acidic peak shifted slightly towards higher temperature suggesting that relatively stronger acidic sites are produced in $\mathrm{H}_{2}$ atmosphere, these were however still weak acid sites. Desorption of $\mathrm{CO}_{2}$ from the surface of catalyst at different temperatures indicates that different basic sites are produced on catalyst surface in argon atmosphere. Observation of $\mathrm{CO}_{2}$ evolution at high temperature corresponds to strong basic sites [25]. When the sample was reduced the desorption peak of $\mathrm{CO}_{2}$ at different temperature merge with each other, 
forming a broad band as shown in Figure-5 (right hand side). This indicates that for the reduced material that there is a wide range of basic site strengths.
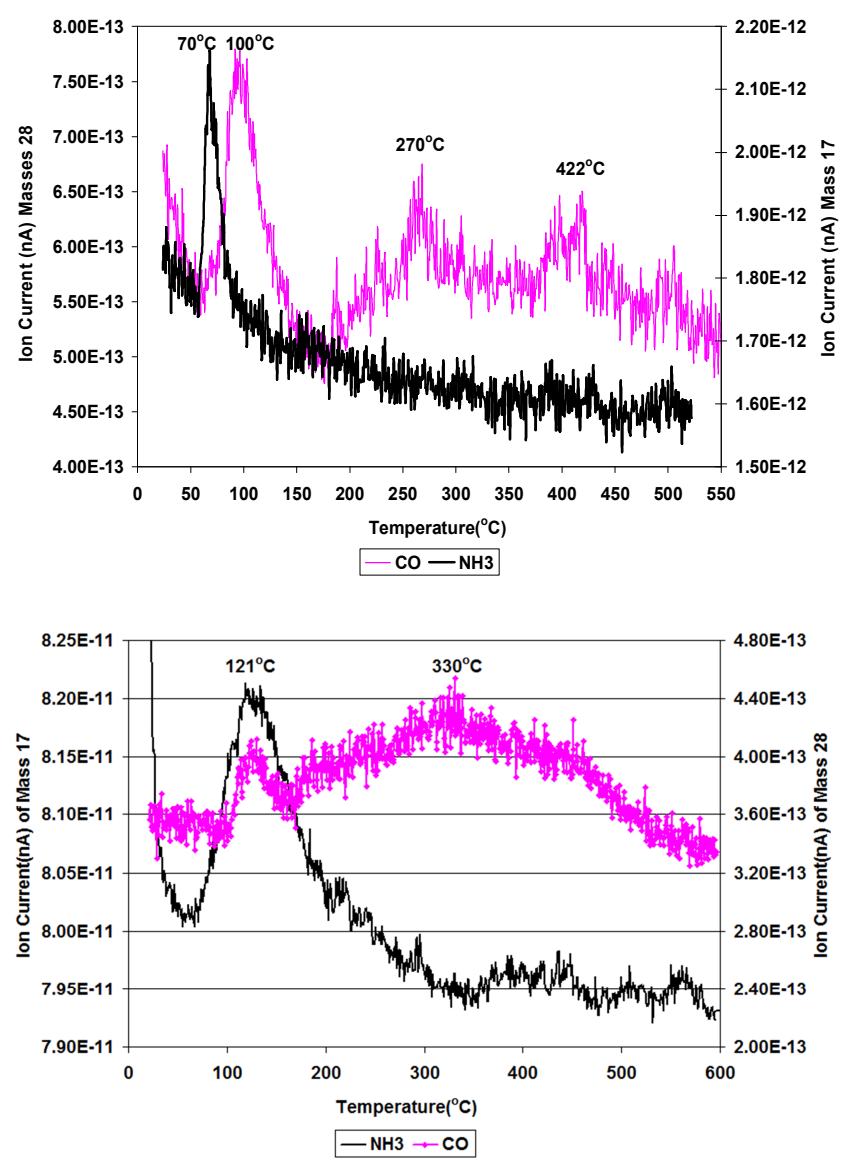

Figure 5. Desorption of $\mathrm{CO}$ and $\mathrm{NH}_{3}$ from Alkali metal/MgO in calcined form (left) and reduced form (right).

\section{Conclusions}

Alkali metal doped $\mathrm{MgO}$ was prepared by impregnation method. The doping of $\mathrm{MgO}$ by alkali metals significantly decreases the BET surface area due to increased agglomeration and sintering of the catalyst. The heat treatment also affects BET surface area because of a crystal phase transition. The doping of alkali metals on $\mathrm{MgO}$ decreases the brucite to periclase phase transformation temperature by about $50^{\circ} \mathrm{C}$. The heat treatment of brucite in different atmosphere modifies the number of acid and base sites. Also the doping of alkali metal on brucite significantly decreased the acidic sites whilst basic sites increased especially in hydrogen atmosphere.

\section{References}

[1] J. Regalbuto, "Catalyst preparation science and engineering", $2^{\text {nd }}$ ed., Taylor \& Francis Group. New York, pp. 107-111, 2007.

[2] A. Corma, "From microporous to mesoporous molecular sieve materials and their use in catalysis", Chemical Reviews. vol. 97(6), pp. 2373-2420, 1997.

[3] S. Pugh, M. J. Gillan, "The energetics of $\mathrm{NH}_{3}$ adsorption at the MgO(001)", Surface Science, vol. 320, pp. 331-343, 1994.

[4] R. Echterhoff, E. Knözinger, "FTIR spectroscopic characterization of the adsorption and desorption of ammonia on $\mathrm{MgO}$ surface" Surface Science, vol. 230(1-3), pp. 237244, 1990.

[5] W. Zhou, I. E. Wachs, C. J. Kiely, "Nanostructural and chemical characterization of supported metal oxide catalysts aberration corrected analytical electron microscopy", Current Opinion in Solid State and Materials Science, vol. 16(1), pp. 10-22, 2012.

[6] F. Arena, F. Frusteri, A. Parmaliana, "Alkali promotion of $\mathrm{Ni} / \mathrm{MgO}$ catalyst" Applied Catalysis A: General, vol. 187(1), pp. 127-140, 1999.

[7] M. Nolan, G. W. Watson, "The electronic structure of alkali doped alkaline earth metal oxides: $\mathrm{Li}$ doping of $\mathrm{MgO}$ studied with DFT-GGA and GGA+U”, Surface Science, vol. 586, pp. 25-37, 2005.

[8] Y. Ferro, A. Allouche, F. Corà, C. Pisani, C. Girardet, "Adsorption of $\mathrm{NH}_{3}$ on $\mathrm{MgO}(100)$ : a comparative study of ab initio and semi-classical calculations" Surface Science, vol. 325, pp. 139-150, 1995.

[9] M. A. Aramendía, J. A. Benítez, V. Borau, C. Jiménez, J. M. Marinas, J. R. Ruiz, F. Urbano, "Study of $\mathrm{MgO}$ and $\mathrm{Pt} / \mathrm{MgO}$ Systems by XRD, TPR and 1H MAS NMR" Langmuir, vol. 15, pp. 1192-1197, 1999.

[10] T. Kanno, M. Kobayashi, "Correlation of the surface basicity of alkali metal- modified MgO evaluated by the 2 parameters" Bulletin of the Chemical Society of Japan, vol. 66(12), pp. 3806-3807, 1993.

[11] Y. Li, D. Nakashima, Y. Ichihashi, S. Nishiyama, S. Tsuruya, "Promotion effect of alkali metal added to impregnated Cobalt catalysts in the gas-phase catalytic oxidation of benzyl alcohol" Industrial \& Engineering Chemistry Research, vol. 43, pp. 6021-6026, 2004.

[12] T. Matsuda, Z. Minami, Y. Shibata, S. Nagano, H. Miura, K. Sugiyama, "Catalytic properties of magnesium oxides doped with sodium compounds" Journal of the Chemical Society, Faraday Transactions 1: Physical Chemistry in Condensed Phases, vol. 82, pp. 1357-1366, 1986.

[13] T. Kanno, M. Kobayashi, "Correlation of the surface basicity of alkali metal- modified MgO", Bulletin of the Chemical Society of Japan, vol. 66, pp. 3806-3807, 1993.

[14] J. Green, "Calcination of precipitated $\mathrm{Mg}(\mathrm{OH})_{2}$ to active $\mathrm{MgO}$ in the production of refractory and chemical grade MgO" Journal of Materials Science, vol. 18, pp. 637- 651, 1983.

[15] A. M. Ghozza, "Surface and catalytic properties of $\mathrm{CuO} / \mathrm{MgO}$ system doped with $\mathrm{K}_{2} \mathrm{O}$ and $\mathrm{Cr}_{2} \mathrm{O}_{3}$ ", Materials Letters, vol. 57, pp. 2120-2129, 2003.

[16] A. S. El-Molla, G. A. El-Shobaky, N. H. Amin, M. N. Hammed, S. N. Sultan, "Catalytic properties of pure and $\mathrm{K}^{+}$doped $\mathrm{CuO} / \mathrm{MgO}$ system towards 2-Propanol conversion", Journal of the Mexican Chemical Society, vol. 57(1), pp. 3642, 2013. 
[17] Y. Ding, G. Zhang, H. Wu, B. Hai, L. Wang, Y. Qian, "Nanoscale magnesium hydroxide and magnesium oxide powders: Control over size, shape and structure via hydrothermal synthesis" Chemistry of Materials, vol. 13, pp. 435-440, 2001.

[18] B. D. Bond, M. P. W. Jacobs, "The thermal decomposition of sodium nitrate", Journal of the Chemical Society A: Inorganic, Physical, Theoretical. A, pp. 1265- 1268, 1966.

[19] T. Yoshida, T. Tanaka, H. Yoshida, T. Funabiki, S. Yoshida, T. Murata, "Study of dehydration of magnesium hydroxide", The Journal of Physical Chemistry, vol. 99, pp. 10890-10896, 1995.

[20] A. V. Dyachenko1, A. S. Opanasuyk, D. I. Kurbatov, S. B. Bolshanina, V. M. Kuznetsov, "Structural properties of magnesium oxide thin films deposited by spray pyrolysis technique", Proceedings of The International Conference Nanomaterials: Applications and Properties, vol. 3(1), pp. 1-4, 2014.
[21] I. F. Guilliatt, N. H. Brett., "Crystal growth in manganesedoped magnesium oxide powders", Journal of the Chemical Society, Faraday Transactions 1: Physical Chemistry in Condensed Phases, vol. 68, pp. 429-433, 1972.

[22] Shriver and Atkins, Inorganic Chemistry. $5^{\text {th }}$ Ed., New York: Oxford University Press, pp. 22-25, 2010.

[23] M. V. Juskelis, J. P. Slanga, T. G. Roberie, A. W. Peters, "A comparison of $\mathrm{CaO}$, beta, and a dealuminated $\mathrm{Y}$ by ammonia TPD and by temperature programmed 2- propylamine cracking", Journal of Catalysis, vol. 138(1), pp. 391-394, 1992.

[24] M. C. Wu, D. W. Goodman, "Acid/base properties of $\mathrm{MgO}$ studied by high resolution electron energy loss spectroscopy", Catalysis letter, vol. 15, pp. 1-11, 1992.

[25] T. Matsuda, J. Tanabe, N. Hayashi, Y. Sasaki, H. Miura, K. Sugiyama, "Properties of magnesium oxides prepared from various salts and their catalytic activity in 1- Butene Isomerization", Bulletin of the Chemical Society of Japan, vol. 55(4), pp. 990-994, 1982. 